\title{
Updated phylogeny of the genus Aeromonas
}

Correspondence

A. J. Martínez-Murcia

ammurcia@mdc-bt.com

\author{
M. J. Saavedra, ${ }^{1,2}$ M. J. Figueras ${ }^{3}$ and A. J. Martínez-Murcia ${ }^{1}$ \\ ${ }^{1}$ Molecular Diagnostics Center (MDC), Biomolecular Technologies S.L. and Universidad Miguel \\ Hernández, 03300 Orihuela, Alicante, Spain \\ ${ }^{2}$ Department of Veterinary Sciences, CECAV-University of Trás-os-Montes e Alto Douro, Vila \\ Real, Portugal \\ Unidad de Microbiologia, Departamento de Ciencias Médicas Básicas, Universidad Rovira i \\ Virgili, 43201 Reus, Spain
}

Species of the genus Aeromonas are common inhabitants of aquatic environments and have been described in connection with fish and human diseases (Altwegg, 1999; Austin \& Adams, 1996; Figueras, 2005; Saavedra et al., 2004). This genus belongs to the family Aeromonadaceae (Colwell et al., 1986; Martínez-Murcia et al., 1992a; Yáñez et al., 2003) and, over the last two decades, the number of recognized species has expanded very rapidly. According to the last edition of Bergey's Manual of Systematic Bacteriology (MartinCarnahan \& Joseph, 2005), the genus comprises the following species: Aeromonas hydrophila, Aeromonas bestiarum, Aeromonas salmonicida, Aeromonas caviae, Aeromonas media, Aeromonas eucrenophila, Aeromonas sobria, Aeromonas veronii (biovars sobria and veronii), Aeromonas jandaei, Aeromonas schubertii, Aeromonas trota, Aeromonas allosaccharophila, Aeromonas encheleia, Aeromonas popoffii and the two DNA homology groups, Aeromonas sp. HG11, Aeromonas sp. HG13 (formerly Enteric Group 501) which remain without a species name. Aeromonas ichthiosmia (Schubert et al., 1990b) and

Abbreviations: AFLP, amplified fragment length polymorphism; HG, homology group.
Aeromonas enteropelogenes (Schubert et al., 1990a) are now considered to be synonyms of $A$. veronii and $A$. trota, respectively (Carnahan, 1993; Collins et al., 1993; Huys et al., 2001, 2002; Martin-Carnahan \& Joseph, 2005). Three novel species, Aeromonas culicicola (Pidiyar et al., 2002), Aeromonas simiae (Harf-Monteil et al., 2004) and Aeromonas molluscorum (Miñana-Galbis et al., 2004), have recently been described. It has been proposed that $A$. culicicola is a synonym of $A$. veronii (Huys et al., 2005), but only the type strain was investigated. In addition, some judicial decisions on certain species names are pending because no Request for an Opinion has yet been submitted to the Judicial Commission of the International Committee on Systematic Bacteriology (http://www.bacterio.cict.fr/a/ aeromonas.html).

The taxonomy of the genus Aeromonas, then, is complex and has been dogged by confusion and controversy. Several DNA-DNA hybridization studies have contributed to the elucidation of the inter-relationships between Aeromonas species, although discrepancies have been reported between different sets of data using the same strains (Esteve et al., 1995a, b; Huys et al., 1996a, b, 2001; Martínez-Murcia, 1999; 
Martínez-Murcia et al., 1992a, 2005). Phylogenetic analyses based on 16S rRNA gene sequencing have indicated that this is a very tight group of species (Martínez-Murcia et al., 1992a). Although most 16S rRNA gene sequence-derived relationships have correlated well with the DNA homology groups (HG), difficulties have been encountered in splitting closely related species (Martínez-Murcia, 1999; MartínezMurcia et al., 2005). DNA probes and restriction fragment length polymorphism (RFLP) profiles designed from 16S rRNA gene diagnostic regions have served to identify Aeromonas at the species level (Ash et al., 1993a, b; Borrell et al., 1997; Dorsch et al., 1994; Figueras et al., 2000; Khan \& Cerniglia, 1997; Lee et al., 2002; Soler et al., 2002). Recent sequencing analyses based on the gene sequences of gyrB (encoding the B subunit of DNA gyrase, a type II DNA topoisomerase) and rpoD (encoding the $\sigma^{70}$ factor, one of the sigma factors that confers promoter-specific transcription initiation on RNA polymerase) have demonstrated that they are excellent molecular markers for phylogenetic inference in the genus Aeromonas (Soler et al., 2004; Yáñez et al., 2003) and these chronometers seem to be well synchronized. The recently described species $A$. simiae (Harf-Monteil et al., 2004) and A. molluscorum (MiñanaGalbis et al., 2004) were not included in these previous studies and only the type strain of A. culicicola (Pidiyar et al., 2002) was available at that time. Therefore, in the present phylogenetic study, an analysis was made of the $g y r B, r p o D$ and $16 \mathrm{~S}$ rRNA gene sequences of all of the currently recognized species of the genus Aeromonas, new isolates of A. culicicola (Figueras et al., 2005) and other Aeromonas strains of uncertain classification (Valera \& Esteve, 2002).

The strains used in this study are listed in Table 1. Strains of A. encheleia and snail isolates were kindly supplied by Drs Esteve and Kodjo; those of A. molluscorum, A. culicicola and A. simiae were from Drs Miñana-Galbis, Pidiyar and HarfMonteil, respectively. Strains were cultivated on tryptic soy agar (Oxoid) at $30^{\circ} \mathrm{C}$ for $24 \mathrm{~h}$. Cultures were harvested and washed in deionized sterile water. Total DNA was extracted and purified. PCR amplification and sequencing of the $g y r B, r p o D$ and 16S rRNA genes were performed following previously described methods (Martínez-Murcia et al., 1999; Soler et al., 2004; Yáñez et al., 2003) although we used the BigDye Terminator V3.1 cycle sequencing kit in the ABI 3100-Avant Genetic Analyser (Applied Biosystems), according to the manufacturer's instructions, and the services supplied by the Molecular Diagnostics Center (MDC), Orihuela, Spain. Nucleotide sequences were aligned by the CLUSTAL_X program, version 1.8 (Thompson et al., 1997). For alignments, previously published reference sequences (Martínez-Murcia, 1999; Martínez-Murcia et al., 1992a; Soler et al., 2004; Yáñez et al., 2003) were used. Genetic distances were obtained by Kimura's two parameter model (Kimura, 1980) and evolutionary trees were constructed by the neighbourjoining method (Saitou \& Nei, 1987) with the MEGA program (Kumar et al., 2001).
The gyrB and $r p o D$ gene sequences showed similar substitution rates, confirming that they are well synchronized as previously demonstrated (Soler et al., 2004; Yáñez et al., 2003). Unrooted phylogenetic trees derived from gyrB (Fig. 1) and rpoD (Fig. 2) gene sequences showed a strain grouping in agreement with all species of the genus Aeromonas described to date, except for Aeromonas culicicola. The original description of A culicicola (Pidiyar et al., 2002) was based on strain MTCC $3249^{\mathrm{T}}$ (=CECT $5761^{\mathrm{T}}$ ) from Culex quinquefasciatus and two strains, SH (MDC56) and SLH (MDC57), from Aedes aegyptii. However, inconsistencies found by Figueras et al. (2005) and now confirmed at the MDC laboratory, suggest that some of the $16 \mathrm{~S}$ rRNA gene sequences of A. culicicola strains could be affiliated to $A$. veronii. Previous phylogenetic studies based on gyrB gene sequences (Soler et al., 2004; Yáñez et al., 2003) included the sequence of strain MTCC $3249^{\mathrm{T}}$ (GenBank accession number AF175891 obtained by V. Pidiyar, M. Patole, A. Kaznowski, and Y. S. Shouche, 2003) which showed five nucleotide differences from that obtained at the MDC laboratory. A duplicate type strain was obtained from the Colección Española de Cultivos Tipo (CECT) and the same differences were confirmed. Similarly, the $\operatorname{gyrB}$ gene sequence of strains SH and SLH (GenBank accession numbers AY130993 and AF488548, respectively) showed a single nucleotide difference. However, the sequences obtained at MDC showed no differences at all and were identical to the sequence submitted under accession number AY130993. The present study included the three original strains (Pidiyar et al., 2002), two isolates, MDC59 and MDC60, from drinking water (Figueras et al., 2005) and three strains recently isolated from ornamental fish (MDC78, MDC285 and MDC364). Strains SH, SLH and the two strains isolated from drinking water clearly clustered within the species $A$. veronii in phylogenetic trees constructed using $g y r B$ and $r p o D$ gene sequences, in agreement with trees constructed from 16S rRNA gene sequences. Following the gyrB gene sequence phylogeny, the type strain of A. culicicola and the three strains isolated from ornamental fish formed a subcluster that was borderline with the group containing the A. veronii strains (Fig. 1). The $r p o D$ gene sequence tree unequivocally grouped all strains within the confines of the A. veronii species (Fig. 2). The present $r p o D$ gene sequence results using seven additional $A$. culicicola strains were in agreement with the recently published proposal that Aeromonas culicicola Pidiyar et al. 2002 should be considered to be a later subjective synonym of Aeromonas veronii Hickman-Brenner et al. 1988 (Huys et al., 2005). The proposal, which used only the type strain, was based on evidence from biochemical characterization, fatty acid analysis, DNA-DNA hybridization and previously reported amplified fragment length polymorphism (AFLP) (MiñanaGalbis et al., 2004) and gyrB/rpoD gene sequence (Soler et al., 2004; Yáñez et al., 2003). DNA-DNA hybridization between the type strains of these two species ranged from 79 to $88 \%$, data that contradict the findings of Pidiyar et al. (2002), who reported a much lower DNA-DNA hybridization value $(44 \pm 3 \%)$. This represents a further example of 
Table 1. Bacterial strains used for $g y r B / r p o D$ gene sequencing in this study and equivalent designations

CECT, Colección Española de Cultivos Tipo, Universidad de Valencia, Valencia, Spain; LMG, BCCM/ LMG Culture Collection, Laboratorium voor Microbiologie, Universiteit Gent, Gent, Belgium; CIP, Collection Bactérienne de l'Institut Pasteur, Paris, France; MDC, Molecular Diagnostics Center, Orihuela, Alicante, Spain; CCUG, Culture Collection, University of Göteborg, Sweden; MTCC, Microbial Type Culture Collection \& Gene Bank, India.

\begin{tabular}{|c|c|}
\hline Strain & Strain designation as received \\
\hline $\operatorname{MDC} 20^{\mathrm{T}}$ & A. molluscorum $848 \mathrm{~T}^{\mathrm{T}}\left(=\mathrm{CECT} 5864^{\mathrm{T}}=\mathrm{LMG} 22214^{\mathrm{T}}\right)$ \\
\hline MDC43 & A. molluscorum 93M (=CECT 5865=LMG 22215) \\
\hline MDC72 & A. molluscorum 431E (=CECT 5866=LMG 22216) \\
\hline MDC73 & A. molluscorum 849T $(=$ CECT $5867=\mathrm{LMG} 22217)$ \\
\hline MDC74 & A. molluscorum $869 \mathrm{~N}$ ( =CECT $5868=\mathrm{LMG} 22218$ ) \\
\hline $\operatorname{MDC} 28^{\mathrm{T}}$ & A. culicicola CECT $5761^{\mathrm{T}}\left(=\right.$ MTCC $\left.3249^{\mathrm{T}}\right)$ \\
\hline MDC56 & A. culicicola $\mathrm{SH}$ \\
\hline MDC57 & A. culicicola SLH \\
\hline MDC59 & A. culicicola 02424 \\
\hline MDC60 & A. culicicola 03037 \\
\hline MDC78 & Aeromonas sp. $\mathrm{O}_{4}$ \\
\hline MDC285 & Aeromonas sp. $\mathrm{A}_{3}$ \\
\hline MDC364 & Aeromonas sp. $\mathrm{B}_{29}$ \\
\hline $\operatorname{MDC} 54^{\mathrm{T}}$ & A. simiae CIP $107798^{\mathrm{T}}\left(=\mathrm{IBS} S 6874^{\mathrm{T}}=\right.$ CCUG $\left.47378^{\mathrm{T}}\right)$ \\
\hline MDC55 & A. simiae CIP 107797 ( = IBS S6652) \\
\hline MDC49 & A. hydrophila E99 (= Kodjo L3) \\
\hline MDC50 & A. hydrophila E100 (= Kodjo L15) \\
\hline MDC51 & A. caviae E103 [=Kodjo Ob3(2)] \\
\hline MDC52 & Aeromonas sp. E104 [=Kodjo B3(41)] \\
\hline MDC61 & A. encheleia CECT 4825 (=LMG $13691=$ CCUG 30347) \\
\hline MDC62 & A. encheleia CECT 4824 (=LMG $13062=$ CCUG 30346) \\
\hline MDC64 & Aeromonas sp. CECT 5028 (=LMG 17060) \\
\hline MDC65 & A. encheleia CECT 5030 (=LMG 17065) \\
\hline MDC66 & A. encheleia CECT 4826 (=LMG $13061=$ CCUG 30345) \\
\hline MDC67 & Aeromonas sp. CECT 4987 (=LMG 17058) \\
\hline MDC69 & Aeromonas sp. CECT 5027 (=LMG 16406) \\
\hline MDC70 & Aeromonas sp. CECT 5025 (=LMG 16403) \\
\hline MDC71 & Aeromonas sp. CECT 4988 (=LMG 17063) \\
\hline MDC24 & Aeromonas sp. HG11 CECT 4856 ( = A926=LMG 13076) \\
\hline MDC98 & A. veronii bv. sobria LMG 13074 (=CECT 4912) \\
\hline MDC99 & A. veronii bv. sobria LMG 13071 (=CECT 4909) \\
\hline MDC100 & A. veronii bv. sobria LMG 13073 (=CECT 4911) \\
\hline MDC45 & Aeromonas sp. S-1 \\
\hline MDC234 & Aeromonas sp. $\mathrm{C}_{8} \mathrm{~A}_{1}$ \\
\hline MDC380 & Aeromonas sp. $\mathrm{AD}_{1} \mathrm{~A}_{3}$ \\
\hline MDC561 & Aeromonas sp. 10562 \\
\hline
\end{tabular}

inconsistency between different sets of DNA-DNA hybridization data published by different authors using the same reference strains (Martínez-Murcia et al., 2005).

The description of the species A. simiae (Harf-Monteil et al., 2004) includes the $16 \mathrm{~S}$ rRNA gene sequences of the only available strains, S6874 and S6652, which had a single nucleotide difference. The sequences of the $16 \mathrm{~S}$ rRNA gene and those of the gyrB and rpoD genes obtained in this study were identical for this pair of strains, suggesting that the two strains may belong to the same clone. This has been further confirmed by using several genotyping techniques (Figueras et al., 2006). In the present study, A. simiae constituted a robust phylogenetic branch with considerable sequence divergence as shown by the two molecular chronometers under evaluation (Figs 1 and 2). A. schubertii was found to be the most closely related species, in agreement with the $16 \mathrm{~S}$ rRNA gene sequence data in the original description (HarfMonteil et al., 2004).

The species A. molluscorum comprises strains 93M, 431E, $869 \mathrm{~N}, 849 \mathrm{~T}$ and the type strain, $848 \mathrm{~T}^{\mathrm{T}}$ (Miñana-Galbis et al., 


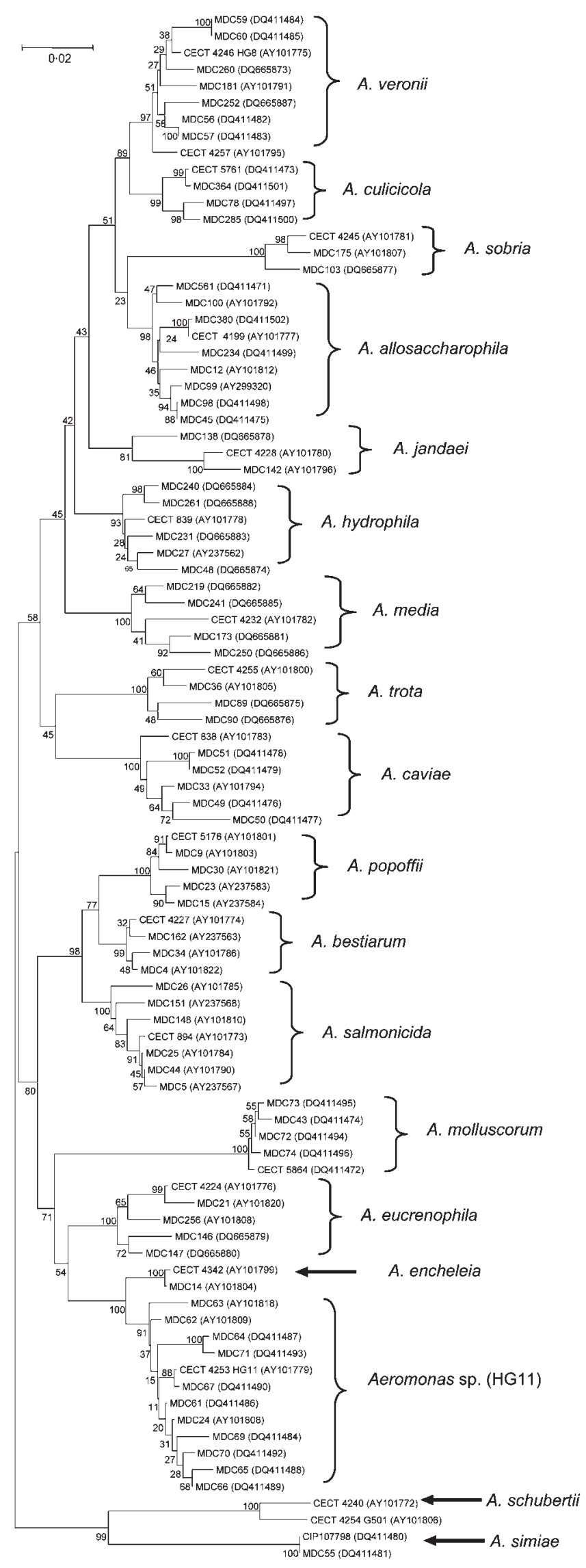

Fig. 1. Unrooted phylogenetic tree based on gyrB gene sequences, showing the relationships of all described Aeromonas species. Numbers shown next to each node indicate bootstrap values (percentage of 1000 replicates). GenBank accession numbers are in parentheses. Bar, 0.02 substitutions per site.

2004). In the species description, genetic typing by AFLP showed that these strains are different from each other and this has since been confirmed by using other genotyping methods (Figueras et al., 2006). The gyrB gene sequence phylogeny indicated that the A. molluscorum strains are different from each other and that they form a tight group

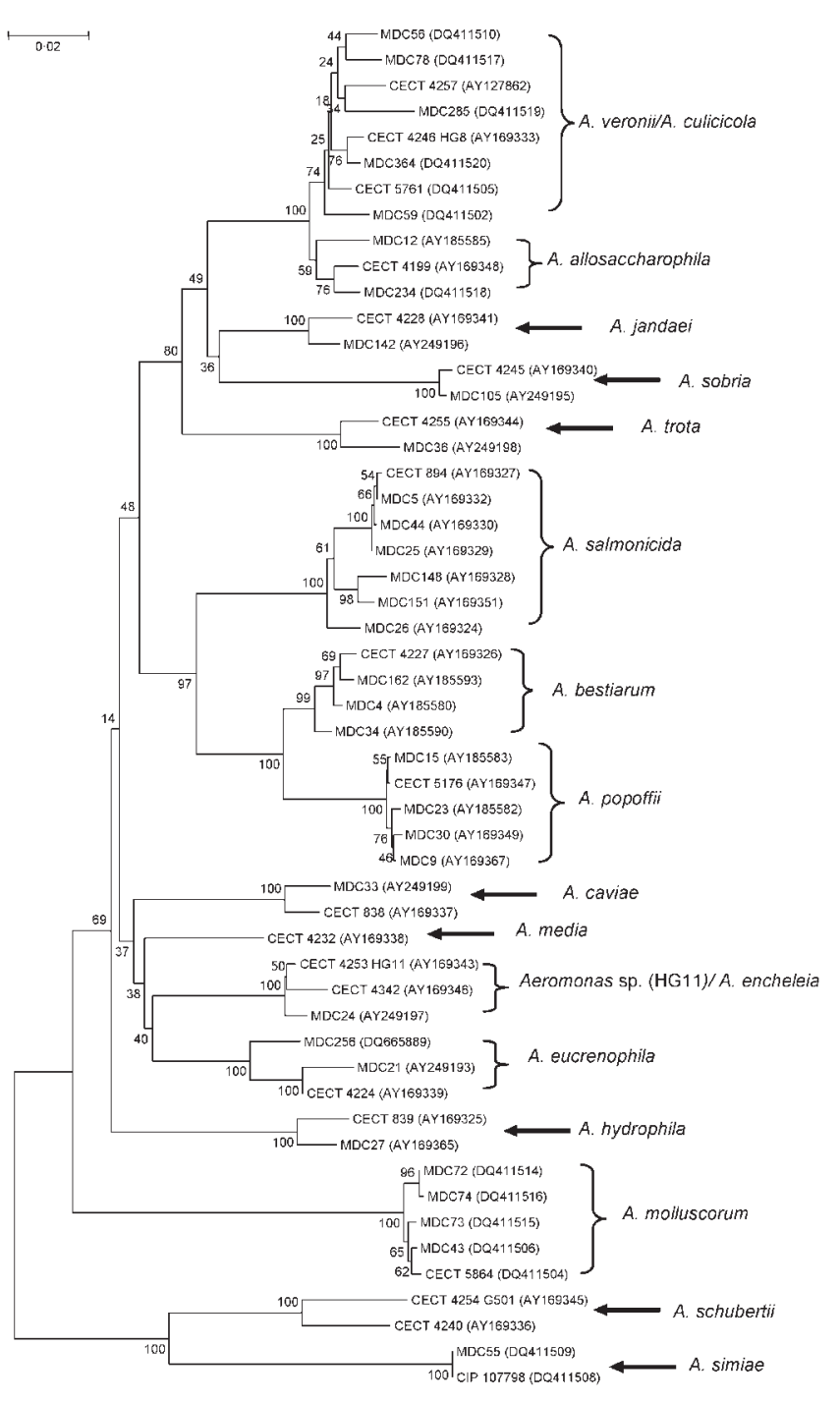

Fig. 2. Unrooted phylogenetic tree based on $r p o D$ gene sequences, showing the relationships of all described Aeromonas species. Numbers shown next to each node indicate bootstrap values (percentage of 1000 replicates). GenBank accession numbers are in parentheses. Bar, 0.02 substitutions per site. 
with a relatively long phylogenetic line (Fig. 1), branched close to A. encheleia, in agreement with the tree based on $16 \mathrm{~S}$ rRNA gene sequences (Miñana-Galbis et al., 2004). The rpoD gene sequences of the A. molluscorum strains were also different from each other and confirmed the phylogenetic distinctiveness of this species (Fig. 2). This finding represents a new case of gyrB (and $r p o D$ ) gene sequences providing the means to split closely related Aeromonas species, even at the intra-species level, when the ability to do so on the basis of $16 \mathrm{~S}$ rRNA gene sequence was limited.

In previous studies based on AFLP fingerprinting and DNADNA hybridization (Huys et al., 1996b, 2001), the original description of the species A. allosaccharophila (MartínezMurcia et al., 1992b) was questioned because a group of strains, including LMG 13071 (=CECT 4909), LMG 13073 (=CECT 4911) and LMG 13074 (=CECT 4912), received as $A$. veronii bv. sobria, clustered with the two known strains of $A$. allosaccharophila. This incongruity with the results from previous DNA-DNA hybridization studies (Esteve et al., 1995a) has been extensively discussed elsewhere (Yáñez et al., 2003). In the present study, the three LMG culture collection strains mentioned above undoubtedly clustered with A. allosaccharophila on the basis of gyrB gene sequence analyses, a cluster clearly separated from that of $A$. veronii, which also contained the reference strain of $A$. veronii bv. sobria. Similar gyrB gene sequence inter-cluster distances have been shown for other Aeromonas species, for instance A. salmonicida and A. bestiarum (Fig. 1) with sufficient evidence to consider them as separate species (Martínez-Murcia et al., 2005). Sequencing of the 16S rRNA gene regions that include diagnostic nucleotides for $A$. allosaccharophila (Martínez-Murcia et al., 1992b) also supports this affiliation (data not shown). This is of particular concern as this material may be part of the AEROLIB laboratory database, a reference for AFLP analysis carried out by the identification service of the Belgian Coordinated Collection of Microorganisms. Recently, thanks to the resolution of $g y r B$ gene sequencing, for the first time since the original species description, we have identified not only 17 A. allosaccharophila strains (e.g. MDC45, MDC234 and MDC380 in Fig. 1; MDC234 in Fig. 2) isolated in a survey from pig carcasses and the processing machinery of a slaughterhouse in the North of Portugal, but also a single strain (MDC561) recently isolated from a clinical case of gastroenteritis (Saavedra et al., 2006). Although the phylogenetic tree based on $r p o D$ gene sequences showed a borderline relationship to the $A$. veronii, the gyrB gene sequence results provided evidence that supports the original proposal of A. allosaccharophila. This species has rarely been isolated before, but is perhaps more widely distributed and only detectable if approaches such as sequencing of housekeeping genes are used.

Finally, four isolates from snails identified by Kodjo et al. (1997) (Table 1), four strains formerly classified as A. encheleia (Demarta et al., 2004) and five aeromonads of uncertain classification on the basis of numerical taxonomy
(Valera \& Esteve 2002; Phenon 19, Aeromonas sp.) were included in the gyrB gene sequence analysis (Fig. 1). The four strains isolated from snails, MDC49-MDC52, clustered with A. caviae, while the other nine strains formed a cluster with the reference strain of Aeromonas DNA homology group 11 (HG11), a group very closely related to the two original A. encheleia strains as previously reported (Huys et al., 1997; Martínez-Murcia, 1999).

As demonstrated in the present phylogenetic analysis, the use of several housekeeping genes is an invaluable approach for the classification of Aeromonas species and for the proper identification of novel closely related isolates. The resolution of the 16S rRNA gene sequence to split species has been superseded by the more variable and synchronized sequences of the gyrB and rpoD genes. As taxonomic conclusions, the present data add support to the species descriptions of $A$. allosaccharophila, $A$. simiae and $A$. molluscorum. However, the relationship between A. culicicola and $A$. veronii remains unclear.

\section{Note added in proof}

While this paper was in press, Aeromonas sharmana sp. nov. has been described [Saha \& Chakrabarti, Int J Syst Evol Microbiol 56 (2006), 1905-1909]. However, in our opinion, the 16S rRNA gene phylogenetic tree presented in the paper indicates that this novel species does not belong to the genus Aeromonas.

\section{Acknowledgements}

This work was supported by grants IMIDTA/2004/369 from IMPIVA, Generalitat Valenciana and FIS03/1183 from the Spanish Ministry of Health. M. J.S was the recipient of a grant (SFRH/BSAB/439/2004) from the Fundação para a Ciência e Tecnologia.

\section{References}

Altwegg, M. (1999). Aeromonas and Plesiomonas. In Manual of Clinical Microbiology, 7th edn, pp. 507-516. Edited by P. R. Murray, E. J. Baron, M. A. Pfaller, F. C. Tenover \& R. H. Yolken. Washington, DC: American Society for Microbiology.

Ash, C., Martínez-Murcia, A. J. \& Collins, M. D. (1993a). Identification of Aeromonas schubertii and Aeromonas jandaei by using a polymerase chain reaction-probe test. FEMS Microbiol Lett 108, 151-156.

Ash, C., Martínez-Murcia, A. J. \& Collins, M. D. (1993b). Molecular identification of Aeromonas sobria by using a polymerase chain reaction-probe test. Med Microbiol Lett 2, 80-86.

Austin, B. \& Adams, C. (1996). Fish Pathogens. In The Genus Aeromonas, pp. 197-244. Edited by B. Austin, M. Altwegg, P. J. Gosling \& S. Joseph. Chichester, UK: Wiley.

Borrell, N., Acinas, S. G., Figueras, M. J. \& Martínez-Murcia, A. J. (1997). Identification of Aeromonas clinical isolates by restriction fragment length polymorphism of PCR-amplified 16S rRNA genes. J Clin Microbiol 35, 1671-1674.

Carnahan, A. M. (1993). Aeromonas taxonomy: a sea of change. 4th International Workshop on Aeromonas/Plesiomonas. Atlanta, GA. Med Microbiol Newsl 2, 206-211. 
Collins, M. D., Martínez-Murcia, A. J. \& Cai, J. (1993). Aeromonas enteropelogenes and Aeromonas ichthiosmia are identical to Aeromonas trota and Aeromonas veronii, respectively, as revealed by small-subunit rRNA sequence analysis. Int J Syst Bacteriol 43, 855-856.

Colwell, R. R., MacDonell, M. T. \& De Ley, J. (1986). Proposal to recognize the family Aeromonadaceae fam. nov. Int J Syst Bacteriol 36, 473-477.

Demarta, A., Huys, G., Tonolla, M., Swings, J. \& Peduzzi, R. (2004). Polyphasic taxonomic study of "Aeromonas eucrenophila-like" isolates from clinical and environmental sources. Syst Appl Microbiol 27, 343-349.

Dorsch, M., Ashbolt, N. J., Cox, P. T. \& Goodman, A. E. (1994). Rapid identification of Aeromonas species using 16S rDNA targeted oligonucleotide primers: a molecular approach based on screening of environmental isolates. J Appl Bacteriol 77, 722-726.

Esteve, C., Gutiérrez, M. C. \& Ventosa, A. (1995a). DNA relatedness among Aeromonas allosaccharophila strains and DNA hybridization groups of the genus Aeromonas. Int J Syst Bacteriol 45, 390-391.

Esteve, C., Gutiérrez, M. C. \& Ventosa, A. (1995b). Aeromonas encheleia sp. nov., isolated from European eels. Int J Syst Bacteriol 45, 462-466.

Figueras, M. J. (2005). Clinical relevance of Aeromonas. Rev Med Microbiol 16, 145-153.

Figueras, M. J., Soler, L., Chacón, M. R., Guarro, J. \& MartínezMurcia, A. J. (2000). Extended method for discrimination of Aeromonas spp. by $16 \mathrm{~S}$ rDNA-RFLP analysis. Int $J$ Syst Evol Microbiol 50, 2069-2073.

Figueras, M. J., Suarez-Franquet, A., Chacón, M. R., Soler, L., Navarro, M., Alejandre, C., Grasa, B., Martínez-Murcia, A. J. \& Guarro, J. (2005). First record of the rare species Aeromonas culicicola from a drinking water supply. Appl Environ Microbiol 71, 538-541.

Figueras, M. J., Alperi, A., Guarro, J. \& Martinez-Murcia, A. J. (2006). Genotyping of isolates included in the description of a novel species should be mandatory. Int J Syst Evol Microbiol 56, 1183-1184.

Harf-Monteil, C., Fleche, A. L., Riegel, P., Prevost, G., Bermond, D., Grimont, P. A. \& Monteil, H. (2004). Aeromonas simiae sp. nov., isolated from monkey faeces. Int J Syst Evol Microbiol 54, 481-485.

Huys, G., Altwegg, M., Hänninen, M.-L. \& 7 other authors (1996a). Genotypic and chemotaxonomic description of two subgroups in the species Aeromonas eucrenophila and their affiliation to A. encheleia and Aeromonas DNA hybridization group 11. Syst Appl Microbiol 19, 616-623.

Huys, G., Coopman, R., Janssen, P. \& Kersters, K. (1996b). Highresolution genotypic analysis of the genus Aeromonas by AFLP fingerprinting. Int J Syst Bacteriol 46, 572-580.

Huys, G., Kämpfer, P., Altwegg, M., Coopman, R., Janssen, P., Gillis, M. \& Kersters, K. (1997). Inclusion of Aeromonas DNA hybridization Group 11 in Aeromonas encheleia and extended descriptions of the species Aeromonas eucrenophila and A. encheleia. Int J Syst Bacteriol 47, 1157-1164.

Huys, G., Kämpfer, P. \& Swings, J. (2001). New DNA-DNA hybridization and phenotypic data on the species Aeromonas ichthiosmia and Aeromonas allosaccharophila: A. ichthiosmia Shubert et al. 1990 is a later synonym of A. veronii HickmanBrenner et al. 1987. Syst Appl Microbiol 24, 177-182.

Huys, G., Kämpfer, P. \& Swings, J. (2002). DNA-DNA reassociation and phenotypic data indicate synonymy between Aeromonas enteropelogenes Schubert et al. 1990 and Aeromonas trota Carnahan et al. 1991. Int J Syst Evol Microbiol 52, 1969-1972.

Huys, G., Cnockaert, M. \& Swings, J. (2005). Aeromonas culicicola Pidiyar et al. 2002 is a later subjective synonym of Aeromonas veronii Hickman-Brenner et al. 1987. Syst Appl Microbiol 28, 604-609.
Khan, A. A. \& Cerniglia, C. E. (1997). Rapid and sensitive method for the detection of Aeromonas caviae and Aeromonas trota by polymerase chain reaction. Lett Appl Microbiol 24, 233-239.

Kimura, M. (1980). A simple method for estimating evolutionary rates of base substitutions through comparative studies of nucleotide sequences. J Mol Evol 16, 111-120.

Kodjo, A., Haond, F. \& Richard, Y. (1997). Molecular and phenotypic features of aeromonads isolated from snails (Helix aspersa) affected with a new summer disease. Zentralbl Veterinarmed B 44, 245-252.

Kumar, S., Tamura, K., Jakobsen, I. B. \& Nei, M. (2001). MEGA2: molecular evolutionary genetics analysis software. Bioinformatics $\mathbf{1 7}$, 1244-1245.

Lee, C., Cho, J.-C., Lee, S.-H., Lee, D.-G. \& Kim, S.-J. (2002). Distribution of Aeromonas spp. as identified by $16 \mathrm{~S}$ rDNA restriction fragment length polymorphism analysis in a trout farm. J Appl Microbiol 93, 976-985.

Martin-Carnahan, A. \& Joseph, S. W. (2005). Order XII. Aeromonadales ord. nov. In Bergey's Manual of Systematic Bacteriology, 2nd edn, vol. 2, Part B, pp. 556-578. Edited by D. J. Brenner, N. R. Krieg, J. T. Staley. New York: Springer.

Martínez-Murcia, A. J. (1999). Phylogenetic positions of Aeromonas encheleia, Aeromonas popoffii, Aeromonas DNA hybridization Group 11 and Aeromonas Group 501. Int J Syst Bacteriol 49, 1403-1408.

Martínez-Murcia, A. J., Benlloch, S. \& Collins, M. D. (1992a), Phylogenetic interrelationships of members of the genera Aeromonas and Plesiomonas as determined by $16 \mathrm{~S}$ ribosomal DNA sequencing: lack of congruence with results of DNA-DNA hybridizations. Int J Syst Bacteriol 42, 412-421.

Martínez-Murcia, A. J., Esteve, C., Garay, E. \& Collins, M. D. (1992b). Aeromonas allosaccharophila sp. nov., a new mesophilic member of the genus Aeromonas. FEMS Microbiol Lett 91, 199-206.

Martínez-Murcia, A. J., Antón, A. I. \& Rodriguez-Valera, F. (1999). Patterns of sequence variation in two regions of the 16S rRNA multigene family of Escherichia coli. Int J Syst Bacteriol 49, 601-610.

Martínez-Murcia, A. J., Soler, L., Saavedra, M. J., Chacón, M. R., Guarro, J., Stackebrandt, E. \& Figueras, M. J. (2005). Phenotypic, genotypic and phylogenetic discrepancies to differentiate Aeromonas salmonicida and Aeromonas bestiarum from each other. Int Microbiol 8, 259-269.

Miñana-Galbis, D., Farfan, M., Fuste, M. C. \& Loren, J. G. (2004). Aeromonas molluscorum sp. nov., isolated from bivalve molluscs. Int J Syst Evol Microbiol 54, 2073-2078.

Pidiyar, V., Kaznowski, A., Narayan, N. B., Patole, M. \& Shouche, Y. S. (2002). Aeromonas culicicola sp. nov., from the midgut of Culex quinquefasciatus. Int J Syst Evol Microbiol 52, 1723-1728.

Saavedra, M. J., Guedes-Novais, S., Alves, A., Rema, P., Tacão, M., Correia, A. \& Martínez-Murcia, A. J. (2004). Resistance to $\beta$-lactam antibiotics in Aeromonas hydrophila isolated from rainbow trout (Oncorhynchus mykiss). Int Microbiol 7, 201-211.

Saavedra, M. J., Perea, V., Fontes, M. C., Martins, C. \& MartínezMurcia, A. J. (2006). Phylogenetic identification of Aeromonas strains isolated from carcasses of pig as new members of the species Aeromonas allosaccharophila. Antonie van Leeuwenhoek (in press). doi: 10.1007/s10482-006-9107-5

Saitou, N. \& Nei, M. (1987). The neighbor-joining method: a new method for reconstructing phylogenetic trees. Mol Biol Evol 4, 406-425.

Schubert, R. H. W., Hegazi, M. \& Wahlig, W. (1990a). Aeromonas enteropelogenes species nova. Hyg Med 15, 471-472.

Schubert, R. H. W., Hegazi, M. \& Wahlig, W. (1990b). Aeromonas ichthiosmia species nova. Hyg Med 15, 477-479. 
Soler, L., Figueras, M. J., Chacón, M. R., Vila, J., Marco, F., MartínezMurcia, A. J. \& Guarro, J. (2002). Potential virulence and antimicrobial susceptibility of Aeromonas popoffii recovered from freshwater and seawater. FEMS Immunol Med Microbiol 32, 243-247.

Soler, L., Yáñez, M. A., Chacon, M. R., Aguilera-Arreola, M. G., Catalán, V., Figueras, M. J. \& Martínez-Murcia, A. J. (2004). Phylogenetic analysis of the genus Aeromonas based on two housekeeping genes. Int J Syst Evol Microbiol 54, 1511-1519.
Thompson, J. D., Gibson, T. J., Plewniak, F., Jeanmougin, F. \& Higgins, D. G. (1997). The CLUSTAL_X windows interface: flexible strategies for multiple sequences alignment aided by quality analysis tools. Nucleic Acids Res 25, 4876-4882.

Valera, L. \& Esteve, C. (2002). Phenotypic study by numerical taxonomy of strains belonging to the genus Aeromonas. J Appl Microbiol 93, 77-95.

Yáñez, M. A., Catalán, V., Apráiz, D., Figueras, M. J. \& Martínez-Murcia, A. J. (2003). Phylogenetic analysis of members of the genus Aeromonas based on gyrB gene sequences. Int J Syst Evol Microbiol 53, 875-883. 